\title{
How to boost the immune defence prior to respiratory virus infections with the special focus on coronavirus infections
}

Samir Jawhara ${ }^{1,2^{*}}$ (1)

\begin{abstract}
The emergence of the novel coronavirus SARS-CoV-2, which causes severe respiratory tract infections in humans (COVID-19), has become a global health concern. One of the most worrying features of COVID-19 is a phenomenon known as the "cytokine storm", which is a rapid overreaction of the immune system. Additionally, coagulation abnormalities, thrombocytopenia and digestive symptoms, including anorexia, vomiting, and diarrhea, are often observed in critically ill patients with COVID-19. Baker's yeast $\beta$-glucan, a natural immunomodulatory component derived from Saccharomyces cerevisiae, primes the immune system to respond better to any microbial infection. Our previous studies have shown that oral administration of yeast $\beta$-glucans decreased the diarrhoea, modulated cytokine expression, and reduced the intestinal inflammation. Additionally, we showed that $\beta$-glucan fractions decreased coagulation in plasma and reduced the activation of platelets. During the period of home confinement facing individuals during the COVID-19 pandemic, our immune defence could be weakened by different factors, including stress, anxiety and poor nutrition, while a healthy diet rich in vitamins $C$ and $D$ can reinforce the immune defence and reduce the risk of microbial infections. Additionally, $\beta$-glucan can be used to strengthen the immune defence in healthy individuals prior to any possible viral infections. This short review focuses on the role of baker's yeast $\beta$-glucan, with a healthy diet rich in natural vitamins $C$ and $D$, in addition to a healthy gut microbiota can provide synergistic immune system support, helping the body to naturally defend prior to respiratory virus infections, until stronger options such as vaccines are available.
\end{abstract}

The emergence of the novel coronavirus SARS-CoV-2, which causes severe respiratory tract infections in humans (COVID-19), has become a global health concern [1-3]. Most coronaviruses cause animal infection but can evolve into strains that are able to infect humans. Coronaviruses, belonging to the family Coronaviridae, are enveloped viruses with positive-stranded RNA [4]. Coronavirus entry into host cells is mediated by an envelopeanchored spike (S) glycoprotein, which is responsible

\footnotetext{
${ }^{*}$ Correspondence: samir.jawhara@univ-lille.fr

${ }^{1}$ CNRS, UMR 8576, UGSF - Unité de Glycobiologie Structurale et

Fonctionnelle, INSERM U1285, Université Lille, 1 Place Verdun, 59000 Lille, France

Full list of author information is available at the end of the article
}

for binding to a host receptor and then fusing viral and host membranes [4]. The analysis of SARS-CoV-2 wholegenome sequence causing COVID-19 is phylogenetically close to two bat-derived SARS-like coronaviruses, bat-SL-CoVZC45 and bat-SL-CoVZXC2, first isolated in Chinese horseshoe bats in 2015-2017 [5, 6]. Tang et al. demonstrated that SARS-CoV-2 genome has evolved into two major prevalent evolvement types, 'L' and ' $\mathrm{S}$ ' types. The 'L-type', which emerged later from 'S type', spreads quickly and is evolutionary more contagious and aggressive than the S-type [7]. In terms of the interaction between SARS-CoV-2 and its host, it has been reported that angiotensin converting enzyme 2 (ACE 2) and serine protease TMPRSS2 are used by the spike protein of SARS-CoV-2 to infect the lung cells as receptors similar

(c) The Author(s) 2020. This article is licensed under a Creative Commons Attribution 4.0 International License, which permits use, sharing, adaptation, distribution and reproduction in any medium or format, as long as you give appropriate credit to the original author(s) and the source, provide a link to the Creative Commons licence, and indicate if changes were made. The images or other third party material in this article are included in the article's Creative Commons licence, unless indicated otherwise in a credit line to the material. If material is not included in the article's Creative Commons licence and your intended use is not permitted by statutory regulation or exceeds the permitted use, you will need to obtain permission directly from the copyright holder. To view a copy of this licence, visit http://creativeco mmons.org/licenses/by/4.0/. The Creative Commons Public Domain Dedication waiver (http://creativecommons.org/publicdomain/ zero/1.0/) applies to the data made available in this article, unless otherwise stated in a credit line to the data. 
to those of SARS-CoV-1 $[8,9]$. Additionally, other studies showed that a high coexpression of ACE2 and TMPRSS2 was also detected in enterocytes, indicating that coronaviruses may infect the gastrointestinal tract and the virus activity may cause enzyme modifications, increasing the susceptibility to intestinal inflammation and diarrhea [10, 11]. Of note, diarrhoea is a frequent symptom in coronavirus infections, it was detected in up to $30 \%$ of patients with MERS-CoV and $10.6 \%$ of patients with SARS-CoV $[12,13]$. Han et al. showed that COVID-19 patients with mild disease severity marked by the presence of digestive symptoms, in particular diarrhoea [14]. These patients showed a longer delay before viral clearance when compared with those with only respiratory symptoms [14].

Viral RNAs, as pathogen-associated molecular patterns (PAMPs), can be recognized by toll-like receptor (TLR)3, TLR7, TLR8 and TLR9, cytosolic receptor melanoma differentiation-associated gene 5, nucleotidyl-transferase cyclic GMP-AMP synthase, and retinoic-acid inducible gene I [15-18]. Sensing of viral RNA by host receptors activates downstream signalling pathways that lead to the induction of immune responses by producing inflammatory cytokines including type I interferon (IFN) and other mediators [19]. Plasma cytokines and chemokines have been observed in COVID-19 patients infected with SARS-CoV-2 [20, 21]. Of note, the SARS-CoV-2 particles first invade the respiratory mucosa and infect other cell types, causing a series of immune responses and the overproduction of cytokines 'cytokine storm, which may be related to the critical condition of COVID-19 patients [21].

Priming the immune system with immunomodulatory components such as $\beta$-glucans can help to prevent the production of a cytokine storm in the body. $\beta$-glucans are major polymers of the Saccharomyces cerevisiae cell wall structure [22]. They play an important role in the structure and function of the yeast cell wall [22]. The cell wall of $S$. cerevisiae contains two types of $\beta$-glucans. Branched $\beta$ - $(1,3)$-glucan accounts for $\sim 50-55 \%$, whereas $\beta$ - $(1$, 6)-glucan represents $10-15 \%$ of total yeast cell wall polysaccharides [22]. Extraction of $\beta$-glucans from S. cerevisiae generally consists of two major steps including yeast cell lysis (separation of the cell wall from the cytoplasm and nucleic acids) and then alkaline hydrolysis with spray-drying (extraction from insoluble cell wall) [23].

$\beta$-glucans derived from $S$. cerevisiae can initiate the innate immune response and then trigger an effective immune response including phagocytosis and cytokine production that leads to fungal elimination [24, 25]. Different studies showed that $\beta$-glucans can act as a training agent which results in amplified immune responses when these trained immune cells are exposed to a secondary stimulus $[26,27]$. Netea et al. reported that training of human monocytes with $\beta$-glucan promotes to enhanced capacity of the immune response to eliminate not only fungi, but also bacteria, viruses and even parasites [27]. The phenomenon of trained innate immunity following exposure to $\beta$-glucan is accompanied by epigenetic mechanisms involving histone modifications, reconfiguration of chromatin and changes in metabolic function that include increased aerobic glycolysis [28, 29]. These epigenetic modifications allow the innate immune cells to acquire a memory phenotype of enhanced immune responses when exposed to a secondary stimulus [28]. It has been reported that soluble $\beta$-glucans are recognized by dendritic cells (DCs) and macrophages present in Peyer's patches and contributed to maturation of DC through the dectin-1 pathway [30]. In addition, we showed that administration of $\beta$-glucans derived from yeasts to mice diminished the overgrowth of Enterococcus faecalis and Escherichia coli populations, and modulated the production of inflammatory mediators [31]. $\beta$-glucan administration increased the production of IL-10 via activation of PPAR $\gamma$, favouring the clearance of Candida glabrata from the gut and the reduction of diarrhoea and colitis [31]. In line with this observation, we showed that in contrast to mannoprotein extracts, oral administration of $\beta$-glucan derived from $S$. cerevisiae reduced intestinal inflammation and promoted the reduction of $C$. albicans overgrowth in the gut [23].

In terms of the effect of $\beta$-glucans on viral infections, administration of $S$. cerevisiae $\beta$-glucan decreased pulmonary lesion score and viral replication, and increased IFN- $\gamma$ and NO levels in pigs infected with swine influenza virus, indicating the role of $\beta$-glucan as a prophylactic option in decreasing of influenza virus infection [32]. In line with this observation, young piglets were exposed to porcine reproductive and respiratory syndrome virus and peripheral blood monocytes were then isolated and exposed to varying concentrations of $\beta$-glucan [33]. $\beta$-glucan induced the production of IFN- $\gamma$ in a dose-dependent manner, suggesting that soluble $\beta$-glucan may improve the innate immune response against this virus [33]. Additionally, the administration of $\beta$-glucans contained in the culture fluid of the yeast Aureobasidium pullulans significantly increased the survival of mice after sub-lethal infection with the PR8-H1N1 strain of influenza virus [34]. Horst et al. showed that daily dietary supplementation with $\beta$-1,3-glucan improved the vaccination response to Newcastle disease virus in chickens [35].

With regard to the comparison of intense versus moderate exercise, in contrast to moderate exercise that may improve immune function, the high-intensity exercise such as a marathon, can temporarily suppress mucosal immunity, and increase the risk of developing upper 
respiratory tract infections [36]. Administration of $\beta$ glucan-derived from yeast induced the production of salivary immunoglobulin A and reduced cold/flu symptomatic days after intense exercise stress in a cohort of 182 individuals [36]. Further investigations showed that $\beta$-glucan supplementation decreased upper respiratory tract infections and improved mood state in stressed individuals, suggesting that it may be a useful approach for reinforcing immune response against daily stressors [37].

Multiple lines of evidence showed that $\beta$-glucans derived from yeasts can block or activate many immune receptors such as dectin-1, CD11b/CD18, or TLRs $[38,39]$. These studies are consistent with our previous reports showing that soluble $\beta$-glucans derived from yeasts are able to modulate the activation of platelets mediated by TLR4 expression [40]. In this study, we showed that $\beta$-glucans at a low concentration in plasma decreases thrombin production and the progressive increase in $\beta$-glucan concentration in plasma reduces coagulation until these $\beta$-glucan fractions no longer affect thrombin production indicating that $\beta$-glucan fractions have activity that is similar to that of low molecular weight heparin [40]. Additionally, $\beta$-glucan fractions decreased the platelet aggregation and the expression of receptors such as P-selectin and activation of integrin $\alpha \operatorname{IIb} \beta 3$. It also reduced platelet activation mediated by TLR4 by increasing the production of TGF- $\beta 1$ and release of ATP [40]. Of note, platelets play an important role in haemostasis, inflammation and pathogen clearance [24]. Recently, a decrease in platelet count has been observed in patients with SARS-CoV-2 [41]. These patients with COVID-19 are at high risk of developing disseminated intravascular coagulation (DIC) and both thrombocytopenia and elevated D-dimer are induced in these patients by the excessive activation of the coagulation cascade and platelets [42]. Multiple pathogenetic mechanisms are involved, including endothelial dysfunction, von Willebrand factor elevation, and TLR activation. These data suggest that the use of prophylactic dose low molecular weight heparin (LMWH) as prophylaxis and monitoring the coagulation status by measuring prothrombin time, platelet count, and D-dimer concentrations in critically ill patients with COVID-19 [42, 43]. In line with these clinical observations, severe COVID-19 is also associated with increased concentrations of proinflammatory cytokines including IL-6 which can induce tissue factor expression on mononuclear cells that initiates coagulation, platelet activation and thrombin generation [20]. Recently, a monoclonal antibody against IL-6 (tocilizumab) emerged as an alternative treatment for COVID-19 patients with a risk of cytokine storms. Guo et al. showed that anti-IL-6 antibody treatment reduced the overreaction of the inflammatory immune responses and boosted immune responses mediated by B cells and CD8 + T cells [44].

Currently, lifestyle changes and psychosocial stress caused by home confinement during the COVID-19 pandemic could disturb our immune defences. Shimamiya et al. showed that the percentage of CD69+lymphocytes decreased during the confinement period [45]. This was mostly caused by changes in the ratio of natural killer (NK) to non-NK lymphocytes suggesting that the stress caused by confinement plays a role in the immune changes observed [45]. Different studies have shown that $\beta$-glucan has a significant role in stress reduction via the inhibition of corticosterone levels and modulation of cytokine production $[46,47]$. Baker's yeast $\beta$-glucan combined with a healthy diet rich in vitamins $C$ and $D$ can be used to boost the immune defence in healthy individuals prior to any possible viral infection. Závorková et al. showed that supplementation with $\beta$-glucan and vitamin $D$ in patients with diabetic retinopathy resulted in significant improvements in high-density lipoprotein levels and a large decrease in total level of cholesterol, supporting the view that $\beta$-glucan and vitamin $\mathrm{D}$ supplementation has a positive effect on human health [48]. In line with this observation, $\beta$-glucan can also increase the effects of vitamin $D$ with positive changes in apolipoprotein A1 metabolism in patients with diabetic retinopathy [49]. Additionally, several studies have demonstrated beneficial effects when $\beta$-glucan was given in combination with vitamin $C[47,50,51]$. An experimental study revealed that combination of glucan-vitamin $\mathrm{C}$ showed notable healing abilities in the treatment of infection by Mesocestoides corti [50]. Konno et al. pointed out that synergistic potentiation of $\beta$-glucan with vitamin $C$ may improve the efficacy of current treatments for various human cancers [52].

Vitamins $C$ and $D$ are well-known to boost the immune response against viral infections [53-57] (Fig. 1). These vitamins have both been implicated in the immune response to several types of respiratory infections, including influenza, respiratory syncytial virus and tuberculosis [53-57]. Hansdottir et al. showed that vitamin D reduces the inflammatory response to respiratory syncytial virus via decreasing the production of cytokines and chemokines in the airways epithelium while maintaining the antiviral state [55]. In addition to vitamins $C$ and $D$, vitamins $\mathrm{B}, \mathrm{E}$, omega-3 fatty acids, carotenoids, polyphenols (flavonoids, phenolic acids), and some minerals ( $\mathrm{Zn}$, $\mathrm{Mn}, \mathrm{Cu}, \mathrm{Se}$ ) can provide health benefits by a synergistic effect, maintaining a proper redox homeostasis [58-60].

In terms of SARS-CoV-2, vitamin D was employed in the early nutritional supplementation of non-critically ill patients hospitalized for COVID-19 disease [61]. Additionally, vitamin $\mathrm{D}$ can modulate the immune response 


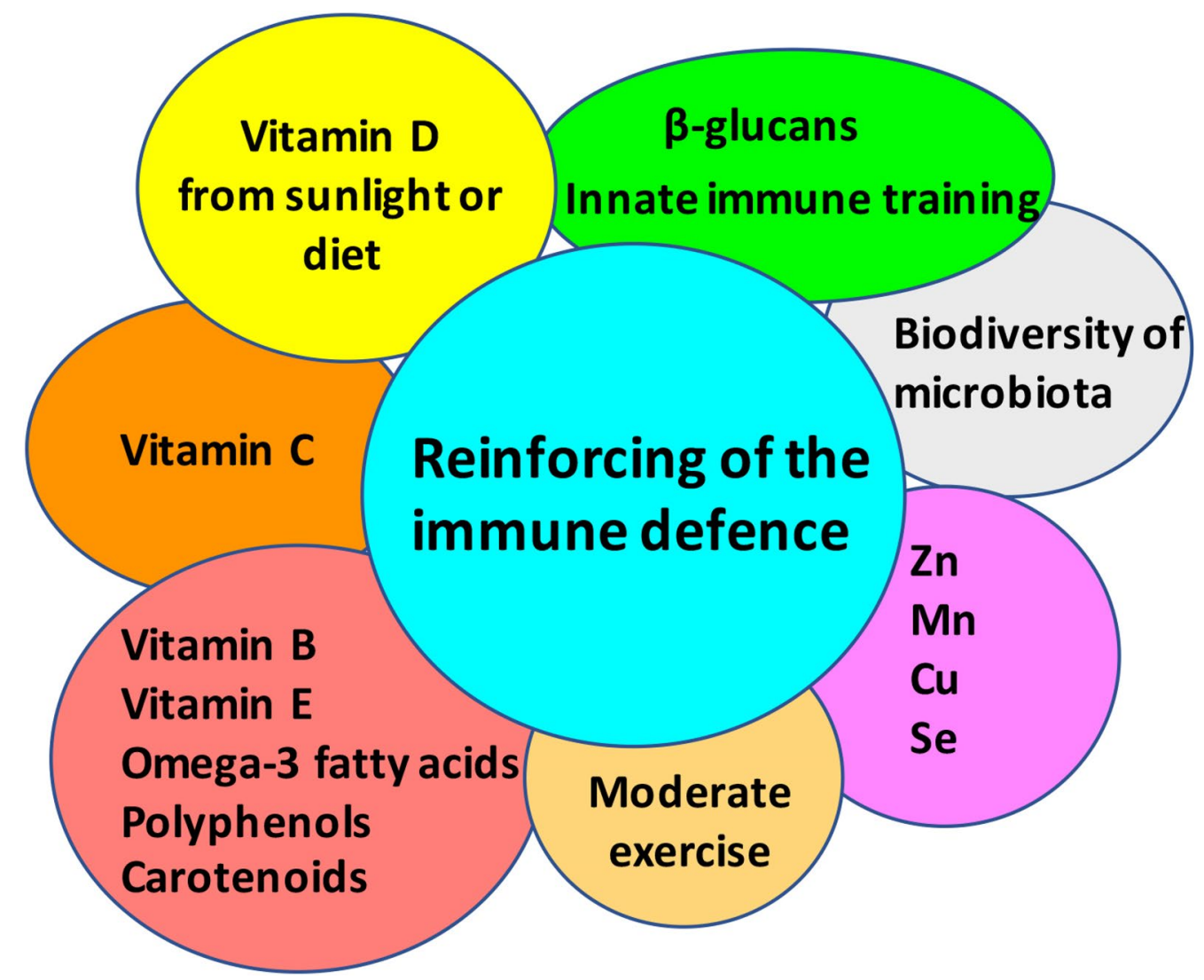

Fig. 1 Schematic overview of how to boost the immune defence prior to respiratory virus infections with a healthy diet including baker's yeast $\beta$-glucan as a prophylactic option, with a healthy diet rich in natural vitamins (A, B, C, D, and E), minerals ( $\mathrm{Zn}, \mathrm{Mn}, \mathrm{Cu}$, Se), omega-3 fatty acids, polyphenols, and healthy microbiota

by reducing the cytokine storm induced by the innate immune system, such as tumour-necrosis factor (TNF)- $\alpha$ and IFN- $\gamma[62]$.

Further investigations demonstrated that elevated vitamin D levels in healthy individuals are associated with down-regulation of pro-inflammatory cytokine production through decreased expression of TLR4 [63]. Grant et al. showed that vitamin D supplementation could reduce the incidence, severity and risk of death from COVID-19 [64]. Recently, Munshi et al. showed an association of vitamin D serum levels with COVID-19 severity and prognosis [65]. Patients with poor prognosis had significantly lower serum levels of vitamin D compared to those with good prognosis supporting that serum vitamin $\mathrm{D}$ levels could be implicated in the COVID-19 prognosis and diagnosis of vitamin $D$ deficiency could be a helpful adjunct in assessing patients' potential of developing severe COVID-19 [65].

In addition to vitamin $D$, vitamin $C$ has been proposed to prevent and treat COVID-19 [66]. A new clinical trial has begun in Wuhan, China, to investigate the role of vitamin C infusion in the treatment of severe SARS-CoV-2 pneumonia [66].
Vitamin D also plays an important role in the gut by reinforcing the integrity of the intestinal barrier and enhancing the tight junctions that control mucosal permeability [67]. The gut microbiota can also be disrupted by stress and poor nutrition during the COVID-19 lockdown. Microbiota diversity is crucial to maintain barrier defences, gut homeostasis and to resist stress, gut infections or metabolic changes. It has been shown that changing the diet to one rich in refined carbohydrates including processing of simple sugars and animal fat leads to an important disruption of the gut microbiota diversity [68]. The gut-lung axis is well-known through cell wall components of the gut microbiota and their metabolites such as short-chain fatty acids that can interact with host PRRs and modulate the immune response [69-71]. With regard to the role of the gut microbiota in the immunomodulation of virus infection, it has been shown that influenza infection can alter the intestinal microbial community by reducing commensal anaerobic bacteria and increasing the Proteobacteria gut population. This occurs via a mechanism that is dependent on type I interferons induced in the pulmonary tract suggesting that 
influenza-induced type I interferons may facilitate secondary Salmonella infection [72]. Recently, Zhejiang et al. observed that some patients with COVID-19 have a disrupted gut microbiota with decreased Lactobacillus and Bifidobacterium populations [73]. Nutritional support and administration of prebiotics or probiotics were proposed to these COVID-19 patients to regulate the balance of the intestinal microbiota and reduce the risk of secondary infections [73]. It therefore appears that it would be better to have a healthy gut microbiota with a high biodiversity prior to any viral infection including coronavirus.

Overall, a combination of baker's yeast $\beta$-glucan as a prophylactic option, with a healthy diet rich in natural vitamins $C$ and $D$, can provide synergistic immune system support, helping the body to naturally defend against viruses. Finally, although all these strategies developed in this short review can help to naturally improve our immune response against any viral infection, still the vaccine, such as the SARS-CoV-2 vaccine when it will be widely available, is the best option to efficiently stop further spread of this virus causing the deadly COVID-19.

\section{Acknowledgements}

Not applicable.

\section{Authors' contributions}

SJ drafted this review. The author read and approved the final manuscript.

\section{Funding}

This work was partially funded by the Agence Nationale de la Recherche (ANR) in the setting of project "InnateFun", promotional reference ANR-16IFEC-0003-05, in the "Infect-ERA" program.

\section{Availability of data and materials}

Not applicable.

\section{Ethics approval and consent to participate}

Not applicable.

\section{Consent for publication}

Not applicable.

\section{Competing interests}

The author declares no conflict of interest.

\section{Author details}

${ }^{1}$ CNRS, UMR 8576, UGSF - Unité de Glycobiologie Structurale et Fonctionnelle, INSERM U1285, Université Lille, 1 Place Verdun, 59000 Lille, France. ${ }^{2}$ University of Lille, 59000 Lille, France.

Received: 17 April 2020 Accepted: 3 October 2020

Published online: 12 October 2020

\section{References}

1. Lin L, Lu L, Cao W, Li T. Hypothesis for potential pathogenesis of SARSCov-2 infection-a review of immune changes in patients with viral pneumonia. Emerg Microbes Infect. 2020;91:727-32.

2. Jawhara S. Could intravenous immunoglobulin collected from recovered coronavirus patients protect against COVID-19 and strengthen the immune system of new patients? Int J Mol Sci. 2020;21:2272.
3. Jawhara S. Can drinking microfiltered raw immune milk from cows immunized against SARS-CoV-2 provide short-term protection against COVID-19? Front Immunol. 2020;11:1888.

4. Li F. Structure, function, and evolution of Coronavirus spike proteins. Annu Rev Virol. 2016:31:237-61.

5. Hu D, Zhu C, Ai L, He T, Wang Y, Ye F, et al. Genomic characterization and infectivity of a novel SARS-like coronavirus in Chinese bats. Emerg Microbes Infect. 2018;71:154.

6. Chan JF, Yuan S, Kok KH, To KK, Chu H, Yang J, et al. A familial cluster of pneumonia associated with the 2019 novel coronavirus indicating person-to-person transmission: a study of a family cluster. Lancet. 2020:395:514-23.

7. Tang X, Wu C, Li X, Song Y, Yao X, Wu X, et al. On the origin and continuing evolution of SARS-CoV-2. Natl Sci Rev. 2020;7:1012.

8. Lu R, Zhao X, Li J, Niu P, Yang B, Wu H, et al. Genomic characterisation and epidemiology of 2019 novel coronavirus: implications for virus origins and receptor binding. Lancet. 2020;395:565-74.

9. Hoffmann M, Kleine-Weber H, Schroeder S, Kruger N, Herrler T, Erichsen S, et al. SARS-CoV-2 cell entry depends on ACE2 and TMPRSS2 and is blocked by a clinically proven protease inhibitor. Cell. 2020;181:271-80.

10. Gu J, Han B, Wang J. COVID-19: gastrointestinal manifestations and potential fecal-oral transmission. Gastroenterology. 2020;1586:1518-9.

11. Hoffmann M, Kleine-Weber H, Schroeder S, Kruger N, Herrler T, Erichsen S, et al. SARS-CoV-2 cell entry depends on ACE2 and TMPRSS2 and is blocked by a clinically proven protease inhibitor. Cell. 2020;1812(271-80):e8.

12. Chan JF, Yuan S, Kok KH, To KK, Chu H, Yang J, et al. A familial cluster of pneumonia associated with the 2019 novel coronavirus indicating person-to-person transmission: a study of a family cluster. Lancet. 2020;39510223:514-23.

13. Fan Y, Zhao K, Shi ZL, Zhou P. Bat Coronaviruses in China. Viruses. 2019;113.

14. Han C, Duan C, Zhang S, Spiegel B, Shi H, Wang W, et al. Digestive symptoms in COVID-19 patients with mild disease severity: clinical presentation, stool viral RNA testing, and outcomes. Am J Gastroenterol. 2020;1156:916-23.

15. Alexopoulou L, Holt AC, Medzhitov R, Flavell RA. Recognition of doublestranded RNA and activation of NF-kappaB by Toll-like receptor 3. Nature. 2001;4136857:732-8.

16. Wu J, Chen ZJ. Innate immune sensing and signaling of cytosolic nucleic acids. Annu Rev Immunol. 2014;32:461-88.

17. Yoo JS, Kato H, Fujita T. Sensing viral invasion by RIG-I like receptors. Curr Opin Microbiol. 2014;20:131-8.

18. Wu J, Sun L, Chen X, Du F, Shi H, Chen C, et al. Cyclic GMP-AMP is an endogenous second messenger in innate immune signaling by cytosolic DNA. Science. 2013:3396121:826-30.

19. Kawasaki T, Kawai T. Toll-like receptor signaling pathways. Front Immunol. 2014;5:461.

20. Huang C, Wang Y, Li X, Ren L, Zhao J, Hu Y, et al. Clinical features of patients infected with 2019 novel coronavirus in Wuhan, China. Lancet. 2020;39510223:497-506.

21. Chen C, Zhang XR, Ju ZY, He WF. Advances in the research of cytokine storm mechanism induced by Corona Virus Disease 2019 and the corresponding immunotherapies. Zhonghua Shao Shang Za Zhi. 2020;360:E005.

22. Aimanianda V, Clavaud C, Simenel C, Fontaine T, Delepierre M, Latge JP. Cell wall beta-(1,6)-glucan of Saccharomyces cerevisiae: structural characterization and in situ synthesis. J Biol Chem. 2009;28420:13401-12.

23. Jawhara S, Habib K, Maggiotto F, Pignede G, Vandekerckove P, Maes $E$, et al. Modulation of intestinal inflammation by yeasts and cell wall extracts: strain dependence and unexpected anti-inflammatory role of glucan fractions. PLoS ONE. 2012;77:e40648.

24. Jawhara S. How fungal glycans modulate platelet activation via toll-like receptors contributing to the escape of Candida albicans from the immune rResponse. Antibiotics. 2020;97:385.

25. Akramiene D, Kondrotas A, Didziapetriene J, Kevelaitis E. Effects of betaglucans on the immune system. Medicina. 2007;438:597-606.

26. Netea MG. Training innate immunity: the changing concept of immunological memory in innate host defence. Eur J Clin Invest. 2013;438:881-4. 
27. Netea MG, Joosten LA, Latz E, Mills KH, Natoli G, Stunnenberg HG, et al. Trained immunity: A program of innate immune memory in health and disease. Science. 2016;352(6284):aaf1098.

28. Greer EL, Shi Y. Histone methylation: a dynamic mark in health, disease and inheritance. Nat Rev Genet. 2012;135:343-57.

29. Mehta S, Jeffrey KL. Beyond receptors and signaling: epigenetic factors in the regulation of innate immunity. Immunol Cell Biol. 2015;933:233-44.

30. Masuda Y, Inoue H, Ohta H, Miyake A, Konishi M, Nanba H. Oral administration of soluble beta-glucans extracted from Grifola frondosa induces systemic antitumor immune response and decreases immunosuppression in tumor-bearing mice. Int J Cancer. 2013;1331:108-19.

31. Charlet R, Bortolus C, Barbet M, Sendid B, Jawhara S. A decrease in anaerobic bacteria promotes Candida glabrata overgrowth while beta-glucan treatment restores the gut microbiota and attenuates colitis. Gut Pathog. 2018;10:50.

32. Jung K, Ha Y, Ha SK, Han DU, Kim DW, Moon WK, et al. Antiviral effect of Saccharomyces cerevisiae beta-glucan to swine influenza virus by increased production of interferon-gamma and nitric oxide. J Vet Med B Infect Dis Vet Public Health. 2004;512:72-6.

33. Xiao Z, Trincado CA, Murtaugh MP. Beta-glucan enhancement of T cell IFNgamma response in swine. Vet Immunol Immunopathol. 2004;1023:315-20.

34. Muramatsu D, Iwai A, Aoki S, Uchiyama H, Kawata K, Nakayama Y, et al beta-Glucan derived from Aureobasidium pullulans is effective for the prevention of influenza in mice. PLoS ONE. 2012;77:e41399.

35. Horst G, Levine R, Chick R, Hofacre C. Effects of beta-1,3-glucan (AletaTM) on vaccination response in broiler chickens. Poult Sci. 2019;984:1643-7.

36. McFarlin BK, Carpenter KC, Davidson T, McFarlin MA. Baker's yeast beta glucan supplementation increases salivary lgA and decreases cold/flu symptomatic days after intense exercise. J Diet Suppl. 2013;103:171-83.

37. Talbott SM, Talbott JA. Baker's yeast beta-glucan supplement reduces upper respiratory symptoms and improves mood state in stressed women. J Am Coll Nutr. 2012;314:295-300.

38. Soloviev DA, Jawhara S, Fonzi WA. Regulation of innate immune response to Candida albicans infections by alphaMbeta2-Pra1p interaction. Infect Immun. 2011;794:1546-58.

39. Brown GD, Gordon S. Immune recognition of fungal beta-glucans. Cell Microbiol. 2005;74:471-9.

40. Vancraeyneste H, Charlet R, Guerardel Y, Choteau L, Bauters A, Tardivel M, et al. Short fungal fractions of beta-1,3 glucans affect platelet activation. Am J Physiol Heart Circ Physiol. 2016;3113:H725-34.

41. Guan WJ, Ni ZY, Hu Y, Liang WH, Ou CQ, He JX, et al. Clinical characteristics of coronavirus disease 2019 in China. N Engl J Med. 2020;38218:1708-20.

42. Tang N, Bai H, Chen X, Gong J, Li D, Sun Z. Anticoagulant treatment is associated with decreased mortality in severe coronavirus disease 2019 patients with coagulopathy. J Thromb Haemost. 2020;185:1094-9.

43. Thachil J, Tang N, Gando S, Falanga A, Cattaneo M, Levi M, et al. ISTH interim guidance on recognition and management of coagulopathy in COVID-19. J Thromb Haemost. 2020;185:1023-6.

44. Guo C, Li B, Ma H, Wang X, Cai P, Yu Q, et al. Single-cell analysis of two severe COVID-19 patients reveals a monocyte-associated and tocilizumab-responding cytokine storm. Nat Commun. 2020;111:3924.

45. Shimamiya T, Terada N, Hiejima Y, Wakabayashi S, Kasai H, Mohri M. Effects of 10-day confinement on the immune system and psychological aspects in humans. J Appl Physiol. 1985;2004(973):920-4.

46. Vetvicka V, Vancikova Z. Anti-stress action of several orally-given betaglucans. Biomed Pap Med Fac Univ Palacky Olomouc Czech Repub. 2010;1543:235-8.

47. Vetvicka V, Vetvickova J. Anti-stress action of an orally-given combination of resveratrol, beta-glucan, and vitamin C. Molecules. 2014;199:13724-34

48. Zavorkova M, Vetvicka V, Richter J, Kral V, Liehnova I, Rajnohova DL. Effects of glucan and vitamin D supplementation on obesity and lipid metabolism in diabetic retinopathy. Open Biochem J. 2018;12:36-45.

49. Richter J, Zavorkova M, Vetvicka V, Liehneova I, Kral V, Rajnohova Dobiasova L. Effects of beta-glucan and Vitamin D supplementation on inflammatory parameters in patients with diabetic retinopathy. J Diet Suppl. 2019;164:369-78.

50. Ditteova G, Velebny S, Hrckova G. Modulation of liver fibrosis and pathophysiological changes in mice infected with Mesocestoides corti (M. vogae) after administration of glucan and liposomized glucan in combination with vitamin C. J Helminthol. 2003;773:219-26.

51. Vetvicka V, Vetvickova J. Combination of glucan, resveratrol and vitamin C demonstrates strong anti-tumor potential. Anticancer Res. 2012;321:81-7.
52. Konno S. Synergistic potentiation of D-fraction with vitamin $C$ as possible alternative approach for cancer therapy. Int J Gen Med. 2009;2:91-108.

53. Urashima M, Segawa T, Okazaki M, Kurihara M, Wada Y, Ida H. Randomized trial of vitamin D supplementation to prevent seasonal influenza $A$ in schoolchildren. Am J Clin Nutr. 2010;915:1255-60.

54. Cannell JJ, Vieth R, Umhau JC, Holick MF, Grant WB, Madronich S, et al. Epidemic influenza and vitamin D. Epidemiol Infect. 2006;1346:1129-40.

55. Hansdottir S, Monick MM, Lovan N, Powers L, Gerke A, Hunninghake GW. Vitamin D decreases respiratory syncytial virus induction of NF-kappaBlinked chemokines and cytokines in airway epithelium while maintaining the antiviral state. J Immunol. 2010;1842:965-74.

56. Carr AC, Rosengrave PC, Bayer S, Chambers S, Mehrtens J, Shaw GM. Hypovitaminosis $C$ and vitamin C deficiency in critically ill patients despite recommended enteral and parenteral intakes. Crit Care. 2017;211:300.

57. Gorton HC, Jarvis K. The effectiveness of vitamin C in preventing and relieving the symptoms of virus-induced respiratory infections. J Manip Physiol Ther. 1999;228:530-3.

58. Kaul TN, Middleton E Jr, Ogra PL. Antiviral effect of flavonoids on human viruses. J Med Virol. 1985;151:71-9.

59. Duthie SJ, Duthie GG, Russell WR, Kyle JAM, Macdiarmid JI, Rungapamestry $V$, et al. Effect of increasing fruit and vegetable intake by dietary intervention on nutritional biomarkers and attitudes to dietary change: a randomised trial. Eur J Nutr. 2018;575:1855-72.

60. Russo M, Moccia S, Spagnuolo C, Tedesco I, Russo GL. Roles of flavonoids against coronavirus infection. Chem Biol Interact. 2020;328:109211.

61. Caccialanza R, Laviano A, Lobascio F, Montagna E, Bruno R, Ludovisi S, et al. Early nutritional supplementation in non-critically ill patients hospitalized for the, 2019 novel coronavirus disease (COVID-19): rationale and feasibility of a shared pragmatic protocol. Nutrition. 2020;2020:110835.

62. Sharifi A, Vahedi H, Nedjat S, Rafiei H, Hosseinzadeh-Attar MJ. Effect of single-dose injection of vitamin D on immune cytokines in ulcerative colitis patients: a randomized placebo-controlled trial. APMIS. 2019;12710:681-7.

63. Khoo AL, Chai LY, Koenen HJ, Sweep FC, Joosten I, Netea MG, et al. Regulation of cytokine responses by seasonality of vitamin D status in healthy individuals. Clin Exp Immunol. 2011;1641:72-9.

64. Grant WB, Lahore H, McDonnell SL, Baggerly CA, French CB, Aliano JL, et al. Evidence that Vitamin D supplementation could reduce risk of influenza and COVID-19 infections and deaths. Nutrients. 2020;12(4):988.

65. Munshi R, Hussein MH, Toraih EA, Elshazli RM, Jardak C, Sultana N, et al. Vitamin D insufficiency as a potential culprit in critical COVID-19 patients. J Med Virol. 2020. https://doi.org/10.1002/jmv.26360.

66. Carr AC. A new clinical trial to test high-dose vitamin $C$ in patients with COVID-19. Crit Care. 2020;241:133.

67. Zhao H, Zhang H, Wu H, Li H, Liu L, Guo J, et al. Protective role of $1,25(\mathrm{OH}) 2$ vitamin D3 in the mucosal injury and epithelial barrier disruption in DSS-induced acute colitis in mice. BMC Gastroenterol. 2012;12:57.

68. Turnbaugh PJ, Backhed F, Fulton L, Gordon J. Diet-induced obesity is linked to marked but reversible alterations in the mouse distal gut microbiome. Cell Host Microbe. 2008;34:213-23.

69. Thorburn AN, McKenzie Cl, Shen S, Stanley D, Macia L, Mason LJ, et al. Evidence that asthma is a developmental origin disease influenced by maternal diet and bacterial metabolites. Nat Commun. 2015;6:7320.

70. Goto H, Sagitani A, Ashida N, Kato S, Hirota T, Shinoda T, et al. Antiinfluenza virus effects of both live and non-live Lactobacillus acidophilus L-92 accompanied by the activation of innate immunity. Br J Nutr. 2013;11010:1810-8.

71. Marsland BJ, Trompette A, Gollwitzer ES. The gut-lung axis in respiratory disease. Ann Am Thorac Soc. 2015;12(Suppl 2):S150-6.

72. Deriu E, Boxx GM, He X, Pan C, Benavidez SD, Cen L, et al. Influenza virus affects intestinal microbiota and secondary Salmonella infection in the gut through type I interferons. PLoS Pathog. 2016;125:e1005572.

73. Xu K, Cai H, Shen Y, Ni Q, Chen Y, Hu S, et al. Management of corona virus disease-19 (COVID-19): the Zhejiang experience. Zhejiang Da Xue Xue Bao Yi Xue Ban. 2020;49(1):147.

\section{Publisher's Note}

Springer Nature remains neutral with regard to jurisdictional claims in published maps and institutional affiliations. 